\title{
Quality of Migrant Care: Results of an Interprofessional Survey
}

Seidel V', Scheffer $\mathbf{B}^{1}$, Heinz $\mathbf{A}^{2}$, Kluge $\mathbf{U}^{2,3}$, Monter $\mathbf{N}^{4}$, Holzgreve $A^{5}$, Inci MG $^{1}$, DemirbukenWegner $\mathrm{E}^{6}$, J onitz $\mathrm{G}^{7}$, Seybold $\mathrm{J}^{8}$ and Sehouli $\mathrm{J}^{1 *}$ ${ }^{1}$ Charite - Universitätsmedizin Berlin, Clinic for Gynecology and Center for Oncological Surgery, Berlin, Germany

${ }^{2}$ Charité - Universitätsmedizin Berlin, Clinic for Psychiatry and Psychotherapy, Campus Mitte, Berlin, Germany

${ }^{3}$ Berlin Institute for Integration and Migration Research (BIM) at the Humboldt University, Berlin, Germany ${ }^{4}$ Psychiatrie Initiative Berlin Brandenburg des Vereins fur Psychiatrie und seelische Gesundheit e. V, Berlin, Germany

5ivantes - Hospital Group, Department of Clinical Research and Academic Teaching, Berlin, Germany ${ }^{6}$ Berlin House of Representatives, Committee for Education, Youth and Family, Berlin, Germany ${ }^{7}$ Berlin Chamber of Physicians, Berlin, Germany ${ }^{8}$ Deputy Medical Director, Charité - Universitätsmedizin Berlin, Berlin, Germany

*Corresponding author: J alid Sehouli, Director of the Clinic of Gynecology with Center for Oncologic Surgery, Universitätsmedizin Berlin Charité, Augustenburger Platz 1, 13353 Berlin, Germany

Received: February 13, 2021; Accepted: March 22, 2021; Published: March 29, 2021

\section{Introduction}

Migration is a global phenomenon and affects every national health care system. According to the 2017 micro census of the German federal statistical office, $23.6 \%$ of Germany's 81.7 million inhabitants were born abroad or had parents born abroad [1]. The percentage of migrants in Berlin is $31.6 \%$ [2]. Previous studies in emergency departments showed that doctors' satisfaction with the course of the treatment they provided is affected by a language barrier [3]. A quantitative survey on 131 midwives and doctors in Berlin's obstetric wards highlighted that medical personnel is often dissatisfied with the care they provide when there are communication problems due to a language barrier [4]. Results of a qualitative study in London and Birmingham support the finding that a language barrier is one of the main factors for medical staff dissatisfaction with the treatment they provide [5]. A study in the Department of Pediatrics of Leipzig University Hospital in Germany also showed that medical staff rated the communication with migrant patients as poor [6]. Despite the imminent importance of this topic, only a few studies address the quality of migrant care. Therefore, this online-based survey among medical doctors and psychotherapists in Berlin was conducted.

This study aims to contribute to the ongoing discussion of the following questions:

(1) How do doctors and psychotherapists rate the quality of care of migrant patients compared to non-migrant patients? (2) How do they experience migrant patient care? (3) What strategies are currently being used to address the challenges in migrant care?

\section{Methods}

All the doctors and psychotherapists of ChariteUniversitatsmedizin Berlin hospitals and Vivantes clinics in Berlin, including all the resident doctors with an outpatient clinic, were invited to participate in this survey. A shortened and adapted version of a questionnaire used in a previous medical staff survey in Berlin was used for this study [7]. The questionnaire was tested on eight persons regarding understandability, acceptance, and reproducibility. It comprised 26 multiple choice questions and four open questions. The survey was conducted online (software: survey-monkey) to achieve a high response rate and ensure anonymity. All the doctors in leading positions were encouraged to invite the physicians and psychotherapists in their departments to participate.

Furthermore, invitations were sent via cooperating organizations such as NOGGO, North-East German Society for Gynecological Oncology (Nord-Ostdeutsche Gesellschaft für Gynakologische Onkologie e.V.) and the Society for Psychiatry and Mental Health (Verein fur Psychiatrie und seelische Gesundheit). This study is thus an exploratory survey. The questionnaire was accessible between January and March 2018 via a weblink sent by email or flyer with a QR 


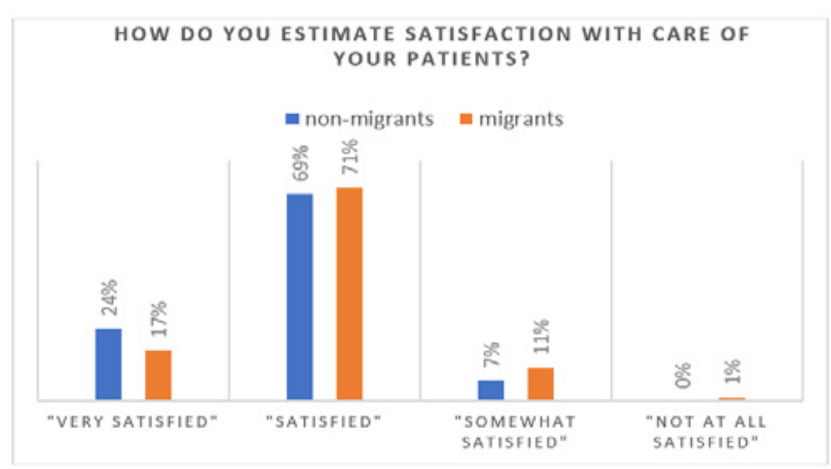

Figure 1: Rating of perceived satisfaction with care depending on migrant status.

(quick response) code. Approval was given by the ethics committee of Charité - Universitätsmedizin Berlin (EA2/168/17). The consent of every staff council of the participating clinics was obtained. The participants gave their informed consent to engage in the study. The data collection was anonymous.

\section{Results}

Within a three month study period, 355 doctors and psychotherapists participated. The study was offered to approximately 2,900 doctors and 1,800 psychotherapists who run outpatient clinics in Berlin and more than 5,000 doctors and psychotherapists who are employed in clinics. The response rate amounts to less than four percent. The results of this study should thus only be regarded as an exploratory survey.

The study cohort was comprised of $96 \%$ (336/350) doctors and $4 \%(14 / 350)$ psychotherapists. Five participants did not specify their professions. Among the psychotherapists, $36 \%$ worked in an outpatient clinic and $64 \%$ in one of the participating clinics. Among the doctors, $75 \%$ worked in clinics. The participants were 59\% (209/354) female and $41 \%(145 / 354)$ male. The majority of them, $86 \%$ (307/355), was born in Germany.

The question, "How high do you estimate the percentage of migrants among your patients?" could be answered with one multiple-choice answer $(0-20 \%, 20-40 \%, 40-60 \%, 60-80 \%$ and $>80 \%)$. Among the participants, $33 \%(\mathrm{~N}=116)$ rated the number of migrants to be $0-20 \%$, and $45 \%(\mathrm{~N}=159)$ estimated that $20-40 \%$ of their patients were migrants. Approximately, a quarter $(23 \%, \mathrm{~N}=80)$ of the participants estimated the percentage of migrants among their patients to be higher than $40 \%$ (40-60\%: $15 \%, \mathrm{~N}=49 ; 60-80 \%: 6 \%$, $\mathrm{N}=21 ;>80 \%: 3 \%, \mathrm{~N}=10$ ). The question, "How high is the percentage of patients with communication problems in German among all migrant patients?" had the same multiple-choice answer possibilities. Half of the participants $(\mathrm{N}=178)$ answered that a language barrier was present in less than $20 \%$ of the migrants under their care. Approximately one-third of the participants reported a language barrier $20-40 \%$ of the time during professional contact with migrants. Of the participants, $56 \%(\mathrm{~N}=199)$ used a language other than German at least once a week to communicate with their patients. At least once a day, communication was not in German among 19\% $(\mathrm{N}=67)$ of the participants. Regarding the language barrier, 58\% $(\mathrm{N}=207)$ of the respondents were dissatisfied at least once a week and 18\% $(\mathrm{N}=63)$ even once a day. Where a language barrier was present, $79 \%(\mathrm{~N}=281)$ of the participants were "always" (39\%, N=139) or "sometimes" (40\%, $\mathrm{N}=142$ ) dissatisfied with their work.

The respondents were also asked to rate the perceived satisfaction among their patients. They estimated that at least $88 \%$ were "satisfied" or "very satisfied" with the care received. Non-migrants, $24 \%$ ( $N=83$ ) were estimated to be "very satisfied", whereas migrant patients, $17 \%$ ( $\mathrm{N}=61)$ were estimated to be "very satisfied". None of the respondents suspected non-migrants to be "not at all satisfied". In comparison, three of the participants raised the concern that migrant patients might, in some cases, be "not at all satisfied" with the care they received (Figure 1).

The respondents regarded different aspects of care as essential for non-migrant and migrant patients. The participants were asked to choose 1-5 among 11 aspects of care, which were most important for these two groups of patients, respectively. For non-migrants, the following four aspects were most often stated: "friendliness and helpfulness" (77\%, N=274), "individual care" (70\%, N=249), "short waiting time" (70\%, N=248), and "understandable information regarding the medical treatment" $(63 \%, \mathrm{~N}=223)$. On the contrary, the participants regarded the following four aspects as crucial for satisfaction concerning migrant patient care: "understandable information regarding the medical treatment" (65\%, N=229), "friendliness and helpfulness" (64\%, N=227), "intercultural competence" (61\%, $\mathrm{N}=216)$ and "language skills of medical staff" (49\%, N=172). Only 31\% ( $\mathrm{N}=108)$ of the participants regarded "short waiting time" as relevant for satisfaction with care for migrant patients.

During the clinical routine, $94 \%$ of the participants resorted to the patient's accompanying person for language interpretation, $58 \%$ to sign language, and $79 \%$ to language skills within the medical staff. Only approximately half of the participants used a professional interpreter when necessary (Figure 2).

Of the participants, $61 \%(\mathrm{~N}=215)$ would like to receive training on delivering care to migrant patients. The majority favors a one-dayseminar over other formats. An e-learning program (22\%), training comprising multiple modules (20\%), and an overview article (13\%) were less interesting for the respondents (Figure 3).

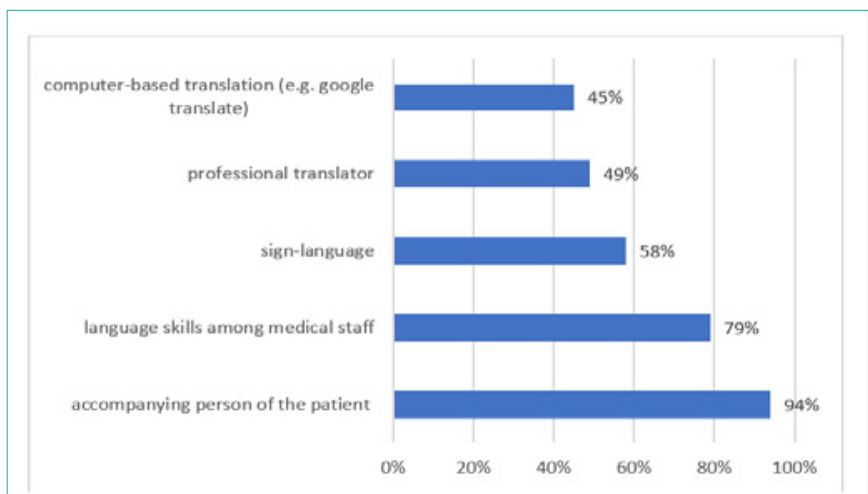

Figure 2: "When you cannot communicate with a patient, what help to you resort to?" Most frequently given answers, multiple answers were possible. 


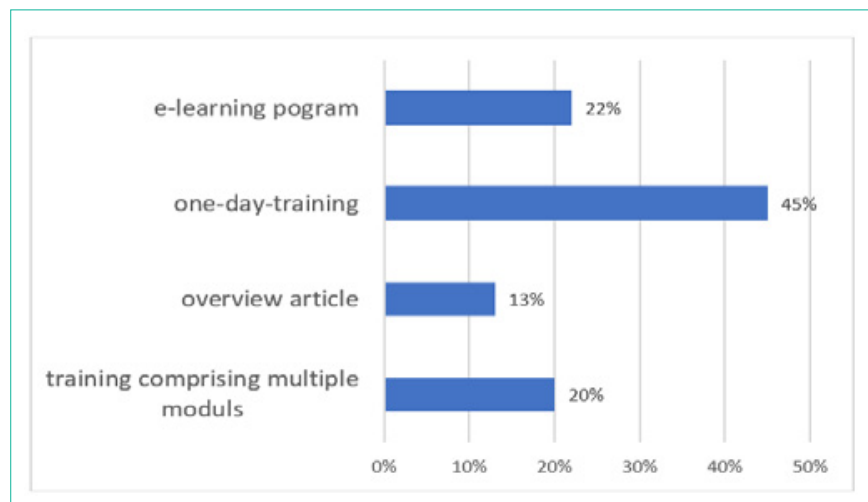

Figure 3: "Which training format do you favor?" Multiple answers were possible.

\section{Discussion}

The study, "Quality of migrant care: results of an interprofessional survey" is an exploratory study on a relevant topic highlighting certain aspects of migrant patient care in Berlin, Germany. This study has important implications in clinical routine.

The participating doctors and psychotherapists generally rated the patient care quality as high regardless of their respective birthplace. The respondents stated frequent stress due to a language barrier. A study among medical staff in Belgian intensive care units found dissatisfaction regarding communication to be one factor associated with higher burn-out rates and intention to leave [8]. This topic should be addressed to prevent burn-out among medical staff in Germany. It should be prospectively studied if, e.g., integration of professional interpreters in medical institutions can increase medical staff satisfaction.

Furthermore, the respondents stated that for migrant patients, the intercultural competence of medical staff and language interpretation should be essential when improving the quality of care. According to this exploratory survey, professional interpretation is not yet fully institutionalized in health care in Berlin. There is space for improvement regarding this topic. The vital link between intercultural communication and tackling healthcare challenges has already been highlighted in previous studies [9-12]. A study in the Charité clinic of gynecology in Berlin showed that migrant patients with good German skills had adequate knowledge about the given treatment in two-thirds of the cases, whereas migrant patients with poor German skills were aware of it in only $50 \%$ of the cases. In contrast, knowledge about the given treatment among non-migrant patients was adequate in more than $80 \%$ of cases [13]. A study on Turkish migrants showed that rehabilitation treatment was less effective due to intercultural communication barriers [14]. Given these shortcomings, a study on psychiatric care for refugees in Berlin showed that using professional interpreters' services prevents wrong diagnoses and unnecessary diagnostics, thus ensuring adequate treatment [15]. This relationship between professional interpretation and higher quality of care and patient safety could was also shown in a systematic review [16].

Many participants in this exploratory survey would like to receive training in intercultural competence. This interest should be timely addressed. In various studies, it was shown that systematic training in intercultural competence could improve patient knowledge and medical staff satisfaction $[17,18]$.

\section{Strength and Limitations}

This is an exploratory study regarding the quality of care for migrant and non-migrant patients in an urban setting in Germany. The study cohort was comprised of a broad interprofessional group of doctors and psychotherapists working in various settings. Few studies have included such a broad interprofessional group of participants. The results of this study can help to improve the quality of care for migrant patients. The study is not representative. Possibly there is a bias towards participants with more interest in the topic of migrant care. The study was only conducted in Berlin, and thus, the results cannot be uncritically extrapolated to other urban or rural settings in Germany. The study only focused on the point of view of the medical staff. Patient perspective should be explored in a further study.

\section{Conclusion}

Structured and systematic training in intercultural competence should be offered to improve the quality of migrant patient care and medical staff satisfaction. Institutionalized professional language translation could possibly improve the satisfaction of migrant patients and medical staff.

\section{References}

1. Bevölkerung und Erwerbstatigkeit: Bevolkerung mit MigrationshintergrundErgebnisse des Mikrozensus 2015-Zugriff. 2017.

2. BPB. 2020.

3. Babitsch B, Braun T, Borde T, David M. Doctor's perception of doctor-patient relationships in emergency departments: What roles do gender and ethnicity play? BMC health services research. 2008; 8: 82.

4. Seidel V, Großkreutz C, Gurbuz B, Vortel M, Henrich W, David M, et al. Personalbefragung zur geburtshilflichen Versorgung von Immigrantinnen in Berlin. Geburtshilfe und Frauenheilkunde. 2019; 79: 453-460.

5. Puthussery S, Twamley K, Harding S, Mirsky J, Baron M, Macfarlane A 'They're more like ordinary stroppy British women': attitudes and expectations of maternity care professionals to UK-born ethnic minority women. Journal of health services research \& policy. 2008; 13: 195-201.

6. Ullrich S, Briel D, Nesterko Y, et al. Verständigung mit Patienten und Eltern mit Migrationshintergrund in der stationären allgemeinpädiatrischen Versorgung. Das Gesundheitswesen. 2016; 78: 209-214.

7. Borde $\mathrm{T}$, David $\mathrm{M}$, Kentenich $\mathrm{H}$. [What Turkish-speaking women expect in a German hospital and how satisfied they are with health care during their stay in a gynecological hospital in Berlin - a comparative approach]. Gesundheitswesen. 2002; 64: 476-485.

8. Vermeir P, Blot S, Degroote S, et al. Communication satisfaction and job satisfaction among critical care nurses and their impact on burn-out and intention to leave: A questionnaire study. Intensive \& critical care nursing. 2018; 48: 21-27.

9. Borde T. Kommunikation und Sprache. Gynäkologische Endokrinologie. 2018; 16: 3-9.

10. Penka S, Schouler-Ocak M, Heinz A, et al. Interkulturelle Aspekte der Interaktion und Kommunikation im psychiatrisch/psychotherapeutischen Behandlungssetting. Bundesgesundheitsblatt-GesundheitsforschungGesundheitsschutz. 2012; 55: 1168-1175.

11. Kluge $U$, Bogic $M$, Devillé $W$, et al. Health services and the treatment of immigrants: data on service use, interpreting services and immigrant staff members in services across Europe. European psychiatry. 2012; 27: S56-S62. 
12. Kluge U. Sprach- und Kulturmittler in der Psychotherapie. In: Machleidt W Kluge U, Sieberer M, et al, Hrsg. Praxis der Interkulturellen Psychiatrie und Psychotherapie Migration und psychische Gesundheit. München: Elsevier, Urban \& Fischer. 2018: 169-180.

13. Pette M, Borde T, David M. Kenntnis über die Diagnose und Therapie ihre Erkrankung bei deutschen und türkischstämmigen Patientinnen vor und nach einem Krankenhausaufenthalt. Journal of the Turkish German Gynecology Association. 2004; 5: 123-130.

14. Schott T, Reutin B, Yilmaz-Aslan Y. Weshalb ist der Rehabilitationserfolg bei Menschen mit türkischem Migrationshintergrund häufig geringer? In, Public Health Forum: De Gruyter. 2015: 79-81.

15. Schreiter S, Winkler J, Bretz J. Was kosten uns Dolmetscher?-Eine retrospektive Analyse der Dolmetscherkosten in der Behandlung von Flüchtlingen in einer Psychiatrischen Institutsambulanz in Berlin. PPmPPsychotherapie. Psychosomatik. Medizinische Psychologie. 2016; 66: 356360.
16. Flores $\mathrm{G}$. The impact of medical interpreter services on the quality of health care: a systematic review. Medical care research and review. 2005; 62: 255299.

17. Beach MC, Price EG, Gary TL. Cultural competence: a systematic review of health care provider educational interventions. Medical care. 2005; 43: 356373.

18. Penka S, Faißt H, Vardar A. Der Stand der interkulturellen Öffnung in der psychosozialen Versorgung-Ergebnisse einer Studie in einem innerstädtischen Berliner Bezirk. PPmP-Psychotherapie. Psychosomatik. Medizinische Psychologie. 2015; 65: 353-362.

19. David M, Borde T, Kentenich H. Die psychische Belastung von Migrantinnen im Vergleich zu einheimischen Frauen-der Einfluss von Ethnizität, Migrationsstatus und Akkulturationsgrad. Geburtshilfe Frauenheilkd. 2002 62: $37-44$. 